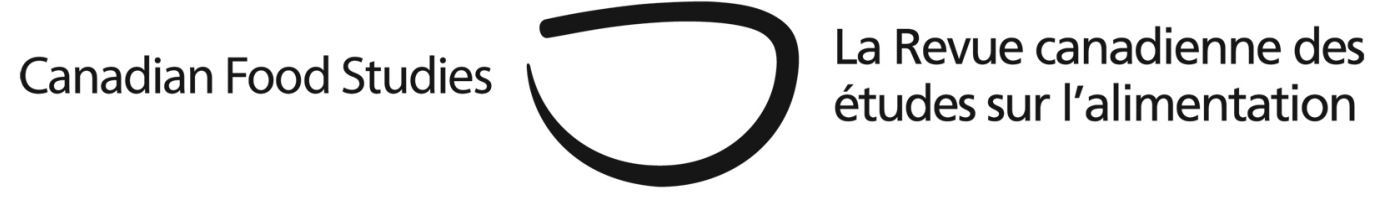

Perspective

\title{
Food studies scholars can no longer ignore the rise of big data
}

\author{
Kelly Bronson ${ }^{a}$ and Irena Knezevic ${ }^{b}$ \\ ${ }^{a}$ Assistant Professor, Science and Technology Studies, St. Thomas University \\ ${ }^{b}$ Assistant Professor, School of Journalism and Communication, Carleton University
}

\begin{abstract}
Our essay invites food scholars to consider how the recent technological developments are making big data increasingly relevant to our field. We offer an overview of the how big data and related crowdsourcing of information are penetrating the production and marketing of food, and reflect on what are potentially key ethical and epistemological questions that link big data with issues of sustainability and social justice in food systems. Our aim is to initiate a more deliberate dialogue between data scholars and food scholars to more comprehensively assess contemporary agri-food environments.
\end{abstract}

Keywords: Big data, crowdsourcing, agricultural “apps”, new agricultural technologies, precision agriculture

Introduction

As big data becomes a site for critical scholarship across many disciplines, scholars caution data enthusiasts that the ways in which big data are generated and used are intimately bound up with 
questions of justice and ethics. For example, how are large data sets used and to whose benefit? Given that many Canadian food studies scholars are deeply concerned with issues of sustainability and social justice vis-à-vis our food systems, might a focus on big data in agriculture intersect with those priorities guiding existing critical inquiry? We think yes, and in our essay we draw inspiration from critical communication studies, food studies, and science and technology studies to lay out suggestions for a cross-disciplinary line of inquiry. Such inquiry could facilitate an improved understanding of how big data trends can support and/or undermine sustainability and social justice in food systems.

In this Perspective essay, we begin by explaining big data and how they are understood in current critical scholarship. We then make links between big data and agri-food systems, and identify the differences between current and past data technologies and data collection. Finally, we probe the potential consequences of this technological development, and we pose research questions that may be of interest to food studies scholars. Exploring how big data complicate current agri-food environments can provide a new forum where food scholars can interrogate the dominant "food regimes"1.Current big data developments may support a productivist food system model at the expense of others, a preference connected with political and economic consequences that challenge some people's very livelihoods, both in cultural and material terms. Given its material consequences, bringing critical data scholarship into the fold of food studies seems a pressing research priority.

\section{What are big data?}

Big data are large sets of data that are organized systematically. Although the term has only been in use for the last few years, big data have existed for decades. They are often longitudinal, but can also be spatial, population-related, or even biological-such as genome sequencing. A familiar example of big data is historical weather information, where large sets of data are organized to enable the relatively accurate prediction of weather patterns for particular geographical areas and times of year.

New technologies have allowed information to be collected at an unprecedented scale, with enormous efficiency, and from non-traditional sources. But big data refers to more than just volume-it also means the technological capability for searching, aggregating, and crossreferencing datasets (Manovich, 2011). This analytical capability, some researchers suggest, represents a new scientific revolution across various spheres from biomedical research to marketing (Anderson, 2008). As well, big data increasingly form the bedrock of modern policy decisions by governments and non-governmental authorities (Gitelman \& Jackson, 2013).

Praise for big data as "revolutionary" fits into the techno-utopic discourses of the democratizing power of Web 2.0 (Anderson, 2008; Shirkey, 2008; Tapscott \& Williams, 2006),

\footnotetext{
${ }^{1}$ Coined by Friedmann and McMichael (1987), the term 'food regimes' is widely used in food studies and refers to capital-centred agri-food systems that are the contemporary norm and are characterized by social inequities.
} 
which is seen as enabling the systematic gathering of "non-expert" knowledge. For example, Shirkey (2008) argues that crowd sourcing initiatives can facilitate input from a wide range of individuals with varying levels of expertise. This can optimize problem solving and collectiverather than technocratic or autocratic_-politics. We all know something about the self-regulating dynamics of "crowds", and how they can result in surprising volume, effectiveness, and accuracy because of our familiarity with now mundane tools like Wikipedia (Giles, 2005).

So whether large-scale search data can help us create better tools, services, and public goods, or whether it will usher in a new wave of privacy incursions and invasive marketing remains an open question. Optimistic big data scholarship, notably, has been matched by a nearly equal measure of critical work (Busch, 2014; Couldry \& Turrow, 2014; Crawford, Miltner, \& Grey, 2014; Elmer, Langlois, \& Redden, 2015). For example, scholars have revealed how much crowd-sourced information is primarily benefitting marketers and other elite interests, rather than the crowd itself (Qualman, 2009). Facebook has been accused and legally tried for the unauthorized collection of user data, from which it is said to profit annually in the billions (Matlack, 2012). Joseph Turow offered a critique of big data and marketing as far back as 2006 in his book Niche Envy, inviting readers to question how these tools interact with our culture and civic life. Not only are scholars drawing attention to the ethical issues associated with big data collection and use, but some are analyzing the epistemological context of digital information (Berry, 2011; Bollier, 2010; Crawford, 2009; 2015). In her work, for example, Kate Crawford interrogates the self-conceptions that are shaped by a "fitbit datasphere", which represents a very narrow range of bodies cultivated through commercial interests (Crawford, 2015). ${ }^{2}$

Big data and agriculture?

Our literature search revealed a lack of scholarly attention paid to big data in food and agriculture. A few articles anticipate the potential value of big data for agribusiness (Campbell, Magnay, Ibrahim, \& Rabatsky, 2014). Two case studies explore social media use in assessing a population's food preferences - one for informing food policy (Shulman, 2003) and the other for food marketing (Tesfom \& Birch, 2010). We found one article describing the potential of big data for transferring technological knowledge to remote farmers in the global South (Hoang, Castella, \& Novosad, 2006). We were unable to find any published critical scholarship on the relationship between big data and agi-food.

Looking back, however, much historical crop monitoring might arguably constitute big data. Farming in the developed world, even at the small scale, is increasingly carried out with computerized tools and by drawing on information in databases. Knowledge, of weather systems for example, is generated through the management, analysis, and interpretation of large volumes

\footnotetext{
${ }^{2}$ For those venturing into big data literature for the first time, we recommend several key works that serve as an excellent introduction to big data and society questions: Boyd and Crawford, 2012; Couldry and Turow 2013; and Kitchin, 2013.
} 
of data. The Agroclimate Impact Reporter, which is Agriculture Canada's application and maps tool, relies on volunteer-submitted weather information to help farmers and industry mitigate weather-related risks. Other aspects of the food system, such as food marketing, are also increasingly supported by big data, such as crowd-sourced information collected with digital tools. Then there are more recent tools like MIT's Sourcemap, which offers both free and commercial databases that track "end-to-end supply chain data: from raw materials to end customers” (sourcemap.com). Sysmos’ Heartbeat poaches social media for information on market trends and consumer interests. The non-profit research organization, Farmers of North America (FNA), is currently testing the AgPriceBook app (short for application) that will "allow farmers to post and find prices on inputs in various categories such as crop protection products and fertilizer" (FNA, 2014).

Non-industrialized farming operations are also increasingly reliant on large sets of digitized data. For instance, a US Department of Agriculture-led LandPKS application (Land Potential Knowledge System, 2015) focuses on agricultural development and extension, providing "mobile and web technologies (that) are being designed to help individuals identify management strategies to sustainably increase production, and that are tailored to their land's unique climate, soils and topography". The international agricultural research consortium, CGIAR, released Seeds4Needs in 2013. This is a tool proclaimed to be a solution for agricultural improvement, including climate change adaptation innovations, policy development, and building farm equity. Far from a futuristic imaginary, big data tools and systems are clearly already a part of agricultural operations the world over.

Farmers have been encouraged to adopt new technologies for data collection, analysis, and monitoring of farm-level systems through appeals to the realization of greater business intelligence. Websites of companies like John Deere and Monsanto promise farmers a level of precision, information storage, processing, and analysis that was previously impossible due to technological limitations. Herein lies the fundamental difference between old and new data technologies: the volume and speed of data gathering and processing means that the consequences of decisions drawn from this information can be immediate and significant. In other words, any potential benefits (to any food system actor) can be realized quickly and efficiently. On the other hand, it also means that errors and skewed decisions can be detrimental to food production and producers at a scale previously unfathomable.

The marketing pitches for such interactive applications-along with sensors, meters, and other data-generating tools-arguably promise farmers the same thing that tractors and recombinant seeds used to do (and still do): “make the farm pay” (Kneen, 1995). John Deere is said to be revolutionizing farming with big data. One description of their digital applications, which connect farm information across millions of users, suggests that these technologies allow farmers to "enhance productivity and increase efficiency"' (van Rijmenan, 2015). Similarly, Monsanto's FieldScripts is described online as bringing in a brighter future as the tool "integrates innovations in seed science, agronomy, data analysis, precision agriculture equipment, and service to provide farmers with hybrid matches and a variable rate planting 
prescription to improve corn yield opportunity” (Monsanto, 2014). These are not new promises; rather, they reflect a long-standing link between the "good life" and the effective application of new technologies to labour (Marx \& Roe-Smith, 1998).

Many technologies have in fact improved the lives of farmers and their ability to produce food, the tractor being an obvious one. But historical trends in North America suggest that those benefits to farmers are typically greatly exceeded by corporate gains. Big data, similarly, have the potential to benefit farmers. Weather-tracking can clearly offer more precise information to farmers to help them make better decisions on the farm. Open access data bases provide great possibilities for peer-to-peer knowledge sharing. A Canadian Federation of Agriculture policy officer suggested to us recently that satellite imagery (a form of big data) can be used to generate low-cost insurance rates for farmers. This is a real possibility and one also identified by the Agroclimate Impact Reporter (mentioned above). He also indicated that apps providing real time commodity and input prices, for instance, can protect farmers from price-gouging (Ross, personal communication, 2015). So big data, as is the case with many technologies, are not inherently dangerous and can potentially improve farm conditions. Unfortunately, corporate trends in agriculture magnify the chance that profit-driven technology use will exceed (in speed and scale) any farm-centred potential of big-data. ${ }^{3}$

Thinking carefully about big data in agriculture: New research directions in food studies?

Food scholars have apparently not yet considered the implications of big data to our field. Even the UK sociologist Lawrence Busch, who has written extensively about the agri-food system, neoliberal food regimes, and emergent technologies (like biotechnology), did not make the connection between big data and agriculture when he recently wrote about the policy implications of big data for the International Journal of Communication (2014). Our cursory scan of recent agricultural technologies suggests that this connection is not only significant, but also raises several important research questions.

One overarching research question at the intersection of food studies and data studies could be: With technological shifts toward the use of large integrated data systems in the agricultural sector, what changes and what stays the same? Arguably, farming has been empirically driven for over a century. The Food Research Institute in the USA and Agriculture Canada's family of research centres were created in the early 1900s to provide empirical information on agriculture. Meticulous accounts were made of wheat yields across farms, weather patterns were analyzed, and soil conditions tracked in order to increase efficiency in

\footnotetext{
${ }^{3}$ That there are corporate benefits attached to big data in agriculture seems evidenced by the recent purchasing habits of Monsanto, which who bought the digital tool developer Climate Corporation in 2013. Climate Corp. itself is acquiring "start-ups” (640 Labs and Solum) who are focused on tools for collecting farm-level information.
} 
wheat production (Anstey, 1986). Another longstanding example of an empirically standardized approach to food and agriculture is the Codex Alimentarius Commission. Established by the Food and Agricultural Organization (FAO) and the World Health Organization (WHO) in 1963, Codex is an international body that promulgates standards, guidelines, and codes of practice in the realm of food safety (Büthe \& Harris, 2011; Halabi, 2015). So what's so new or different about big data? As previously stated, surely the volume of information and the analytical potential of contemporary computer technologies for collecting agricultural data represent a shift. Yet, we think that systematically tracing the historical developments, and charting the affordances as well as the limitations of various empirical approaches, is worthy of research attention among food studies scholars.

Additionally, we can ask: Are there agricultural systems that cannot easily be accounted for by data gathering tools that take in only quantitative data? For example, holistic farm management surely depends on such a broad variable set and a systemic view that it might not easily fit into a quantitative framework. Moreover, if quantifiable data are the tool through which policies are made and assessed, there may be negative consequences for agricultural priorities that cannot easily be quantified - for example, the role of family farms in community vitality of rural areas, or the benefits of farm biodiversity. These kinds of inquiries centre around what we might call the "politics of quantification" (Hacking, 1992; Nowotny, 1991; Porter, 2000). Scholars have pointed out that institutions like Codex, with standardized forms of expert reasoning, have helped to solidify particular scientific frameworks (in their case for risk analysis) that embody particular value choices regarding health, environment, and the dispensation of regulatory power; therefore they advantage particular actors in the food system (Winickoff \& Bushey, 2010). Other research has pointed out how risk analysis frameworks for agricultural biotechnologies in Canada fail to account for the concerns of many farmers because these concerns cannot fit into a reductionist framework. Thus social, political, and cultural concerns over agricultural biotechnologies are ignored in quantitative risk analyses (Bronson, 2014). These insights into the politics of empirical frameworks evoke the need for food studies scholars to address such work on big data tools and frameworks.

Closely related are the larger questions of power relationships cited in critiques of contemporary food regimes (Clapp, 2012; Friedmann, 2009; Koç, Sumner, \& Winson, 2012; McMichael, 2009). Those critiques often rely on political economic analysis, and comment on the inequities that seem inseparable from the industrial food system. So how are these power relationships changed or perpetuated under big data? More precisely, are there profit-generating uses of farm-level data that extend beyond the farmer? Who exactly is using these data and for what benefit? The National Farmers Union (2003) has tracked the massive disparity between farm-level income (even including economically successful farmers) and the profits of large food corporations. Do we see a perpetuation of these relationships of inequity under big data? It would be useful for tracking the profit margins of John Deere under the broad move towards, in their words, farming “forward” (van Rijmenan, 2015). 
While key concerns here may have to do with data ownership and economic inequity, we suspect that the issues are even more complex. Whereas crowdsourcing big data tools do rely on farmers' knowledge, they do not necessarily invite farmers to shape the context in which that knowledge is collected. A long history of research in science and technology studies tells us that technological devices contain possibilities for ordering human activity. By far the greatest latitude of choice for what the final order will look like is the very first time a particular instrument is introduced. Choices tend to become fixed into material equipment, economic investment, legal infrastructure, and habits of thought and speech (Bronson, 2015). So who has a role in deciding precisely which kinds of data are to be collected, given the design of big digital tools? Are there farming systems (like holistic farm management systems) whose types of data cannot be captured by apps targeting highly reductionist, quantitative information? Will these farming systems that exceed the technological logic of big data remain in the background of agricultural development?

We predict that particular agricultural systems and foodways are perpetuated not just in the design and use of big data-say, for the disproportionate gain of powerful agri-food corporations_-but also in the marketing of big data technologies. In what ways do the images circulating in the marketing of big data tools normalize particular farming systems? It is obvious that the imagined typical user for John Deere's big data tools is a farmer who unproblematically adopts the newest technologies — not just digital weather apps but also a completely automated or smart house. The imagery of John Deere's Farm Forward marketing campaign is imbued with a longstanding cultural bias against farming strategies which cannot be "rationally managed" as technology-maximizing, profit-oriented businesses (Kneen, 1995). Food studies scholars have already clearly established that techno-utopian promises about the bright future of agriculture under new technologies (tractors, hybrid seeds, chemicals, GMOs) have not only proved misleading but also dangerous (Esteva, 1996; Kneen, 1995; Moore Lappé, 1971; Patel, 2007).

Big data are poised to challenge-or possibly reproduce-relations among food system players, and we think that they deserve attention by food studies scholars. We have raised questions that carry cultural, political, ecological, and material significance. A more deliberate and sustained dialogue between data scholars and food scholars is a pressing research priority.

\section{References}

Anderson, C. (2008). The end of theory: The data deluge makes the scientific method obsolete. Wired. Retrieved from http://www.wired.com/2008/06/pb-theory

Anstey, T.H. (1986). One hundred harvests: Research Branch, Agriculture Canada 1886-1986. Ottawa: Canadian Government Publishing Centre. 
Berry, D. (2011). The computational turn: Thinking about the digital humanities, Culture Machine, vol. 12. Retrieved from http://www.culturemachine.net/index.php/cm/article/view/440/470

Bollier, D. (2010). The promise and peril of big data. Retrieved from www.aspeninstitute.org/sites/default/files/content/docs/pubs/The_Promise_and_Peril_of_ Big_Data.pdf

Bronson, K. (2014). Reflecting on the science in science communication. Canadian Journal of Communication, special issue on STS, 39(4), 523-537.

Bronson, K. (2015). Responsible to whom? Seed innovations and the corporatization of North American agriculture. Journal of Responsible Innovation, 2(1), 62-77.

Boyd, D., \& Crawford, K. (2012). Critical questions for big data. Information, Communication \& Society, 15(5), 662-679.

Busch, L. (2014). A dozen ways to get lost in translation: Inherent challenges in large-scale data sets. International Journal of Communication, 8, 1727-1744.

Büthe, T., \& Harris, N. (2011). Codex Alimentarius Commission. In T. Hale \& D. Held (Eds.), Handbook of Transnational Governance: Institutions and Innovations (pp.219-229). Cambridge, UK: Polity.

Campbell, T., Magnay, J., Ibrahim, S., \& Rabatsky, B. (2014). “Jumping into the Future: How LeapfrogTechnologies will Change Agriculture.” Webinar via Rural Sociological Society, Retrieved from http://www.partneringforinnovation.org/leap-frog-tech.aspx

CGIAR. (2013). Seeds4Neeeds. Retrieved from https://ccafs.cgiar.org/tags/seeds4needs

Clapp, J. (2012). Food. Cambridge: Polity.

Couldry, N., \& Turow, J. (2014). Advertising, big data, and the clearance of the public realm: Marketers' new approaches to the content subsidy. International Journal of Communication, 8, 1710-1726.

Crawford, K. (2015). The partial witness: Data, bodies and the trouble with truth. March 10, 2015 Attallah Lecture. Ottawa: Carleton University. Available at http://www.partneringforinnovation.org/leap-frog-tech.aspx 
Crawford, K., Miltner, K., \& Gray, M.L. (2014). Critiquing big data: Politics, ethics, epistemology. International Journal of Communication, 8, 1663-1672

Crawford, K. (2009) Following you: Disciplines of listening in social media, Continuum: Journal of Media \& Cultural Studies, 23,(4), 532-533.

Elmer, G., Langlois, G., \& Redden, J. (2015). Compromised Data: From Social Media to Big Data. London: Bloomsbury

Esteva, G. (1996) Hosting the otherness of the other: The case of the Green Revolution. In F. Apfel-Marglin,\& S.A. Marglin. (Eds.), Decolonizing Knowledge: From Development to Dialogue (pp. 249-278). Clarendon: Oxford University Press.

Farmers of North America (FNA). (2014). New app allows farmers to share input prices. Retrieved from http://fna.ca/new-app-enables-farmers-to-share-input-prices-2/

Friedmann, H., \& McMichael, P. (1987). Agriculture and the state system: the rise and fall of national agricultures, 1870 to the present. Sociologia Ruralis, 29 (2), 93-117.

Friedmann, H. (2009). Feeding the empire: The pathologies of globalized agriculture. Socialist Register, 41, 124-143.

Giles, J. (2005). Internet encyclopaedias go head to head. Nature, 438, 900-901.

Gitelman, L. \& Jackson, V. (2013). Introduction. In L. Gitelman (Ed). “Raw data” is an oxymoron (pp.1-14). Cambridge, MA: MIT Press.

Hacking, I. (1992). Statistical language, statistical truth and statistical reason: The selfauthentication of a style of reasoning. In E. McMullin (Ed.), Social dimensions of science (pp. 130-157). Notre Dame, IN: Notre Dame University Press.

Halabi, S.F. (2015). The Codex Alimentarius commission, corporate influence, and international trade: A perspective on FDA's global role. American Journal of Law \& Medicine, 41 (23), 406-421.

Hoang, L.A., Castella, J.C., \& Novosad. P. (2006). Social networks and information access: Implications for agricultural extension in a rice farming community in northern Vietnam. Agriculture and Human Values, 23(4), 513-527. 
Jasanoff, S., \& Martello, M. (2004). Earthly politics: Local and global in environmental governance. Cambridge, MA: MIT Press.

Kitchin, R. (2013). Big data and human geography: Opportunities, challenges and risks. Dialogues in Human Geography, 3(3), 262-267.

Kneen, B. (1995). From Land to Mouth: Understanding the Food System. (2nd edition). Toronto: NC Press Ltd.

Koç, M., Sumner, J., \& Winson, A. (Eds). (2012). Critical Perspectives in Food Studies. Toronto: Oxford University Press.

Land Potential Knowledge System. (2016). Homepage. Retrieved from http://landpotential.org

Manovich, L. (2011). Trending: the promises and the challenges of big social data. In M.K. Gold, (Ed.), Debates in the Digital Humanities (pp. 460-475). Minneapolis, MN: The University of Minnesota Press. Retrieved from http://www.manovich. net/DOCS/Manovich_trending_paper.pdf

Marx, L., \& Roe-Smith, M. (1994). Does technology drive history? The dilemma of technological determinism. Cambridge, MA: MIT Press.

Matlack, C. (2012, January 12). Who Do You Trust More with Your Data: Facebook or a Bank?, Bloomberg Business. Retrieved from http://www.bloomberg.com/bw/magazine/who-doyou-trust-more-with-your-data-facebook-or-a-bank-01122012.html

McMichael, P. (2009). A food regime genealogy. Journal of Peasant Studies, 36(1), 139-169.

Monsanto. (2014). Fieldscripts. Retrieved from http://www.monsanto.com/products/pages/fieldscripts.aspx

Moore Lappé, F. (1971). Diet for a Small Planet. New York: Ballantine Books.

National Farmers Union (NFU). (2003). The farm crisis, bigger farms, and the myths of “competition” and “efficiency”. Union Farmer Monthly, 54(7), 13-25.

Nowotny, H. (1990). Knowledge for certainty: Poverty, welfare institutions and the institutionalization of social science. In P. Wagner, B. Wittrock, \& R. Whitley (Eds.), Discourses on society XV (pp. 23-41). Dordrecht, the Netherlands: Kluwer. 
Patel, R. (2007). Stuffed and starved: Markets, power and the hidden battle for the world's food system. Toronto: HarperCollins

Porter, T. (1995). Trust in numbers: The pursuit of objectivity in science and public life. Princeton, NJ: Princeton University Press.

Qualman, E. (2009). Socialnomics: How social media transforms the way we live and do business. London, UK: John Wiley \& Sons.

Shirkey, C. (2008). Here Comes Everybody. New York, NY: Penguin.

Shulman, S.W. (2003). An experiment in digital government at the United States National Organic Program. Agriculture and Human Values, 20(3), 253-265.

Tapscott, D., \& Williams, A.D. (2006). Wikinomics: How mass collaboration changes everything. Old Saybrook, Connecticut: Tantor Media.

Tesfom, G., \& Birch, N. (2010). Do they buy for their dogs the way they buy for themselves? Psychology and Marketing, 27(9), 898-912.

Turow, J. (2006). Niche envy: Marketing discrimination in the digital age. Cambridge, MA: MIT Press.

van Rijmenan, M. (2015). John Deere is revolutionizing farming with big data. Datafloq. Available from: https://datafloq.com/read/john-deere-revolutionizing-farming-big-data/511

Winickoff, D. \& Bushey, D. (2010). Science and power in global food regulation: The rise of the Codex Alimentarius. Science, Technology and Human Values, 53(3), 356-381. 